\title{
Robust Back-stepping Based Higher Order Sliding Mode Control of Non-Inverted Buck-Boost Converter for a Photovoltaic System
}

Research Article

\author{
Shaukat Ullah* \\ Sarhad University of Science and Information Technology, Peshawar, Pakistan
}

Received: February 14, 2021; Accepted: July 01, 2021

\begin{abstract}
Photovoltaic (PV) system generates renewable energy from sunlight, which has low efficiency due to the variance in nature of temperature and irradiance in a fast changing environment condition. Different researchers have proposed different maximum power point tracking MPPT techniques to improve the efficiency. However, still there are many open issues. Thus, to address this, a non-linear back-stepping-based higher order sliding mode controller (BHOSMC) is proposed to harvest maximum power from PV system. The PV module and load is interfaced by a non-inverted buck-boost converter (NIBBC). A linear interpolation method is used for voltage generation and Lyapunov stability is used to verify the control system equation. MATLAB/Simulink software is used for testing the proposed controller performance. The experimental result verified that the proposed BHOSMC is robust, accurate and fast tracking, faultless and less chattering as compared to perturb and observe (P\&0), back-stepping control (BSC) and back-steppingbased sliding mode control under rapidly varying meteorological condition.
\end{abstract}

Keywords: MPPT • buck-boost converter • non-linear control • back-stepping • higher order sliding • photovoltaic PV

\section{Introduction}

Sun is a very prominent source of renewable energy, which is converted into electrical energy by photovoltaic panel; and this generated energy can be deployed in various applications (Dincer, 2011). It is recognised as the most demanded resource of energy that determines the development of economy as well as social growth. The optimisation of sustainable energy reduces the energy crises at global level (Gohar Ali and Arbos, 2020). When population increases, the requirements for facilities increase; in turn, this results in the increase of demand for energy (Smith, 2009). Photovoltaic (PV) system has exhibited a non-linear current-voltage and power-voltage characteristics, which change with the temperature of the solar cell and irradiance of the solar cell (Gohar Ali et al., 2020). We know that the generation of power using conventional types of energy is getting decreased continuously and also its prices increase, which can be observed in the case of fossil fuels; and moreover, fossil fuels pollute the environment. So, in this regard, unconventional energy resources are better to fulfil the energy demand and obtain environmentally clean energy.

PV does not have any bodily motion and can be utilised in a combination of mechanical framework, where the two frameworks are very unique (Zhang et al., 2013).

Our objective is to design a controller that gives good performance under fault and uncertainties, has less chattering and less rise time and is robust.

Perturb \& observed (P\&O) method is used for harvesting high power from PV module. This algorithm works on the principle of perturbation, which causes the PV module a continuous variation. The perturbation moves in the same direction when there is an increase in power. And after that power has reached its peak, then there will be a decrease in power and so perturbation reverses. For keeping the peak power oscillation small, the perturbations 


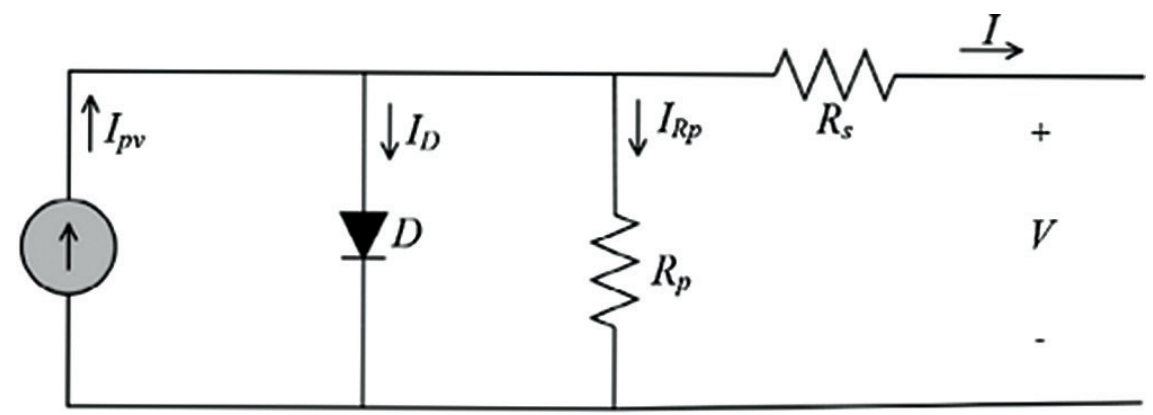

Fig. 1. Equivalent model of PV system.

size should be kept small. Voltage (V) and Current (I) should be determined by P\&O method to find output power (Metry et al., 2016). For getting maximum power point MPP, the perturbation periodically repeat itself. This technique is good for achieving MPP but have some shortcomings like slow convergence and non-robustness; it gets stuck in when running (Sera, 2013).

The disadvantage of P\&O is achieved by the incremental conductance IC method in a fast changing metrological condition (Elgendy et al., 2012). This method is used to check whether the MPPT is reached its highest point and the perturbing is stopped at operating point. This technique works on the $-\mathrm{I} / \mathrm{V}$ and $\mathrm{dl} / \mathrm{dV}$ relationship. The relationship shows that MPPT is at the right side when the $\mathrm{dP} / \mathrm{dV}$ has negative value. When it is positive, the MPP is on the left side (Elgendy et al., 2012). The P\&O method oscillates at MPP, and IC method traces quickly the decreasing and increasing irradiance levels and also has more accuracy than P\&O. There are also some shortcomings in IC such as high cost because of using four sensors as well as due to high power losses, and thus it is not perfect (Hua and Shen, 1998). So we have to look for another method.

Artificial Neural Network (ANN) is a technique used to achieve results better than other techniques. ANN algorithm is pre-planned coding and data that start the operation by giving inputs and it has fixed time for processing. It is fast but a complex system coding that works only on the specified parameters (Elobaid et al., 2015). These techniques work in two cascaded ANNs namely ANN1 and ANN2 to estimate the reference voltage of PV to achieve high power. The voltage and current of PV panels is at ANN1 input. The temperature and irradiance is checked by the first neural network ANN1. And it is used for the input of second neural network ANN2.

The back-stepping is a recursive technique that stabilises the system origin in a form that is based on strict feedback. The reference of the regression plane is effectively traced by using back-stepping-based non-linear controller (Iftikhar et al., 2018), which produces the $\mu$ input, and by the use of Lyapunov function that stabilises the system and determines the duty cycle forwarded to switch in non-inverted buck-boost converter (NIBBC).

In this article, a non-linear back-stepping-based higher order sliding mode controller (BHOSMC) is proposed. The proposed controller tracks the high MPP by the NIBBC (Başoğlu et al., 2016). The reference voltage generated by the linear interpolation technique in a regression plan. The non-linear controller is proposed due to the non-linear behaviour of the non-inverted buck-boost converter (El Fadil and Giri, 2007).

\section{PV Module Modelling}

First of all we have to design a PV module which has the exact variables like P-V and I-V characteristics that would communicate with the NIBBC. Figure 1 shows the equivalent model of PV module which is labelled through specific rating (Villalva et al., 2009). All the variables and constants used in the given model are labelled in order to find the exact values of current and voltages (Bellia et al., 2014).

The module consists of current source $I_{p v}$, which depends upon the temperature and irradiance. The other component is diode $\mathrm{D}$ in which current $\mathrm{I}_{D}$ flows through. Parasitic resistance, $\mathrm{R}_{r p}$, is connected parallel to the diode $D$ and $R_{s}$ is the series resistance.

Now applying Kirchhoff's current law, we have:

$$
I=I_{p v}-I_{d}-I_{r p}
$$


where $I$ is the output of PV panel current (Armghan et al., 2018), and $I_{r p}, I_{p v}$ and $I_{d}$ can be related as shown below:

$$
I_{p v}=\left(\frac{G}{G_{s t d}}\right)\left(I_{p v, s t d}+K\left(T-T_{s t d}\right)\right)
$$

In the above equation, $I_{p v}$ is $P V$ cell current, standard condition of irradiance is $G_{\text {std }}$, the current generated by the solar cell at standard temperature and standard irradiance is $I_{p v, s t d}$. $T$ and $T_{s t d}$ are the temperatures of PN junction at general and standard form, respectively, $G$ and $G_{\text {std }}$ are the irradiance at general and standard form, respectively, and $\mathrm{K}$ is Boltzmann constant.

$$
I=I_{0}\left(\exp \frac{q\left(V+R_{s} I\right)}{\gamma K T}-1\right)
$$

In Eq. (3) the $I_{0}$ shows the reverse saturation current, which is given in the following equation-

$$
\mathrm{I} 0=\frac{I_{p v, s t d}+\mathrm{K}\left(\mathrm{T}-T_{s t d}\right)}{\exp \left(\frac{\mathrm{q} V_{o c}+K_{v}\left(\mathrm{~T}-T_{s t d}\right)}{\gamma V_{t}}-1\right)}
$$

where $\gamma$ is the ideal gain factor of a diode while the electron charge is $q, P V$ system open circuit voltage is $V_{\text {oc }}$, PV module thermal voltage is represented by $V_{t}$, coefficient of short circuit is $K_{i}$ and coefficient of open circuit is $K_{v}$.

$$
I_{r p}=\frac{V+R_{s} I}{R_{p}}
$$

Now, we have to substitute the value of $I_{p v}, I_{d}$ and I from Eqs (2), (3) and (5) in Eq. (1). Then we get the following equation:

$$
I=\left(\frac{G}{G_{s t d}}\right)\left(I_{p v, s t d}+K_{i}\left(T-T_{s t d}\right)\right)-I_{0}\left(\exp \frac{q\left(V+R_{s} I\right)}{\gamma}-1\right)-\frac{V+R_{s} I}{R_{p}}
$$

Now solving Eq. (6), we get the equation for complete PV module.

$$
I=N_{p}\left\{I_{p v}-I_{0}\left[\exp \left(\frac{V+R_{s} I}{\frac{N_{s} K T}{q} \gamma}\right)-1\right]\right\}-\frac{V+R_{s} I}{R_{p}}
$$

Here, $R_{p}, R_{s}$ are the parasitic and series resistances of solar cell, respectively, $V$ is the output voltage, $N_{p}$ is the number of cell connected in parallel and $\mathrm{N}_{\mathrm{s}}$ is the number of cells in series.

\section{NIBBC Modelling}

In order to step-down or step-up a DC voltage, a DC-DC buck-boost converter is used. In the proposed technique a NIBBC is used. It is used to boost the low input to the required level and buck the high input to the required level. As it is non-inverted, the polarity at the input will be same as the polarity to the output. By changing the duty cycle of the 


\section{$\mathrm{L}$}

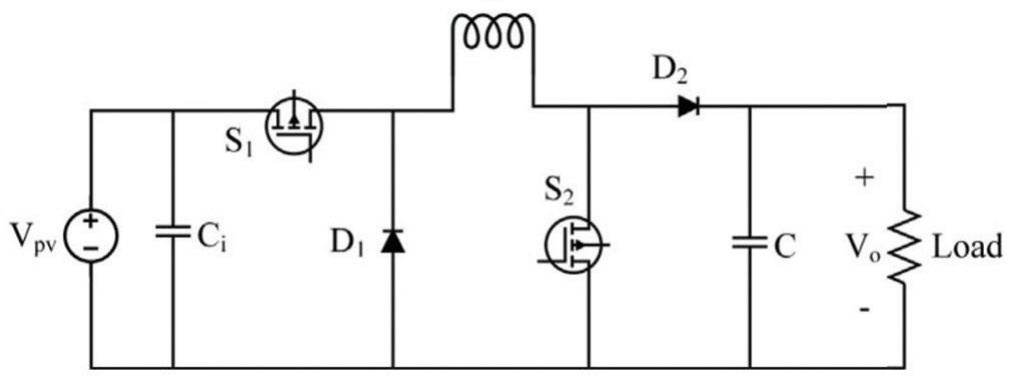

Fig. 2. Circuit diagram of NIBBC. NIBBC, non-inverted buck-boost converter.

NIBBC with the help of back-stepping BHOSMC, the output voltage $\left(\mathrm{V}_{\mathrm{pv}}\right)$ is shifted to the desired value (Armghan et al., 2018). The circuit of NIBBC is shown in Figure 2.

The main components of NIBBC and used nomenclature in Figure 2 are as follows: diodes $\left(D_{1}, D_{2}\right)$, Insulated gate bipolar transistor IGBT (Insulated-gate bipolar transistor) switches $\left(\mathrm{S}_{1}, \mathrm{~S}_{2}\right)$, inductor $\mathrm{L}, \mathrm{V}_{\mathrm{pv}}-$ the input voltage from $P V$, capacitors $\left(C_{i}\right.$ and $\left.C\right)$ and load $(R)$.

Suppose the NIBBC is working in the continuous conduction mode and has two modes of operating, which are mode 1 and mode 2. The switches of mode 1 are in ON condition and the switches of mode 2 are in off condition.

In mode 1, the switches of IGBT $S_{1}$ and $S_{2}$ are in ON position. In the circuit in Figure 2, the diode $\left(D_{1}\right)$ is reverse biased, the path is closed by the switch $\left(\mathrm{S}_{2}\right)$ and the load is disconnected. The PV input charges the L inductor by $\mathrm{S}_{1}$ in mode 1.

Applying Kirchhoff's current law and voltage law, the following equations are obtained:

$$
\begin{aligned}
& I_{c i}=I_{p v}-I_{l} \\
& \frac{d V_{p}}{d t}=\frac{I_{p v}}{C_{i}}-\frac{I_{l}}{C_{i}} \\
& V_{l}=V_{p v} \\
& \frac{d I_{l}}{d t}=\frac{V_{p v}}{L} \\
& I_{c}=\frac{-V_{o}}{R} \\
& \frac{d V_{o}}{d t}=\frac{-V_{o}}{R C}
\end{aligned}
$$

In Figure 2, the two switches $S_{1}$ and $S_{2}$ both are in OFF position. The $L$ inductor is connected with the load through $D_{2}$. By using Kirchhoff's law, we get:

$$
\begin{aligned}
& I_{c i}=I_{p v} \\
& \frac{d V_{p v}}{d t}=\frac{I_{p v}}{C_{i}} \\
& V_{l}=-V_{o} \\
& \frac{d I_{l}}{d t}=\frac{V_{o}}{L}
\end{aligned}
$$




$$
\begin{aligned}
& I_{c}=I_{l}-\frac{V_{o}}{R} \\
& \frac{d V_{C}}{d t}=\frac{I_{l}}{C}-\frac{V_{o}}{R C}
\end{aligned}
$$

Now, from capacitor charge balance and inductor volt-second, we get:

$$
\begin{aligned}
& \frac{d V_{p v}}{d t}=\frac{I_{p v}}{C_{i}}-u \frac{I_{l}}{C_{i}} \\
& \frac{d I_{l}}{d t}=u \frac{V_{p v}}{L}+u \frac{V_{o}}{L}-\frac{V_{o}}{L} \\
& \frac{d V_{C}}{d t}=\frac{i L}{C}+\frac{V_{o}}{R C}-u \frac{I_{l}}{C} \\
& V_{o}=\frac{u}{1-u} V_{i n}
\end{aligned}
$$

By supposing ideal power transfer to be $P_{i}=P_{0}$, this can be written as:

$$
R_{p v}=\frac{(1-D)^{2}}{D^{2}} R_{o}
$$

We can model it for one switching period in an average form. Let the average of $\mathrm{V}_{\mathrm{pv}}$ be $\mathrm{x}_{1}$ and the average value of IL be $x_{2}$; and the average of $V_{c}$ be $x_{3}$ and $\mu$ be the average of $u$.

Then we can write as:

$$
\begin{aligned}
& x_{1}=\left\langle V_{p v}\right\rangle \\
& x_{2}=\left\langle I_{l}\right\rangle \\
& x_{3}=\left\langle V_{C}\right\rangle \\
& \mu=\langle u\rangle
\end{aligned}
$$

So, Eq. (14) becomes-

$$
\begin{aligned}
& x_{1}^{\grave{\mathrm{U}}}=\frac{I_{p v}}{C_{i}}-\mu \frac{x_{2}}{C_{i}} \\
& \dot{\mathrm{U}}=-\frac{x_{3}}{C_{i}}+\mu \frac{x_{1}+x_{2}}{L} \\
& x_{2} \\
& \dot{\mathrm{U}}=\frac{x_{2}}{R C}-\frac{x_{3}}{R C}-\mu \frac{x_{2}}{C}
\end{aligned}
$$

We have found the equation of NIBBC for PV system, which then interfaces with the back-stepping BHOSMC. 


\section{Controller Design}

To control the maximum power point tracking due to changing temperature and irradiance, we use non-linear proposed controller, which is better than conventional back-stepping and $\mathrm{P} \& \mathrm{O}$ techniques.

\subsection{Reference voltage generation by Linear Interpolation Method}

Linear interpolation method is used to generate reference voltage. The reference voltage is gained from the regression plane which is derived by linear interpolation. The regression is shown in Figure 3. The temperature and irradiance is the input of the $\mathrm{PV}$ and Vpvr is the output of the PV. . We take the temperature, $\mathrm{T}$, ranges from $\left(0^{\circ}\right.$ to $\left.75^{\circ}\right)$ and similarly irradiance, $G$, ranges from $\left(200 \mathrm{~W} / \mathrm{m}^{2}\right.$ to $\left.1,200 \mathrm{~W} / \mathrm{m}^{2}\right)$. The proposed controller tracks the $\mathrm{V}_{\mathrm{pv}}$ from $\mathrm{V}_{\mathrm{pvr}}$ to get the MPP. The equation of the regression plane is given as:

$$
V_{r e f}=574.824-0.112500 * G-2.0468 * T
$$

\subsection{BHOSM MPPT control design}

For harvesting maximum power from photovoltaic module, a non-linear back-stepping BHOSMC is designed to track the output voltage of $V_{p v}$ by the control of the duty cycle of the NIBBC. So, we have to define the error signal first.

$$
e_{1}=V_{p v}-V_{r e f}
$$

The objective is to make $e_{1}$ zero.

The derivative of Eq. (22) versus time it yields.

$$
\dot{e}=\dot{V}_{p v}-V_{r e f}^{\dot{U}}
$$

Inserting $\mathrm{V}_{\mathrm{pv}}$, from Eq. (18) in Eq. (23), gives the following expression:

$$
\dot{e}_{1}=\frac{I_{p v}}{C_{i}}-\mu \frac{x_{2}}{C_{i}}-\dot{V}_{r e f}
$$

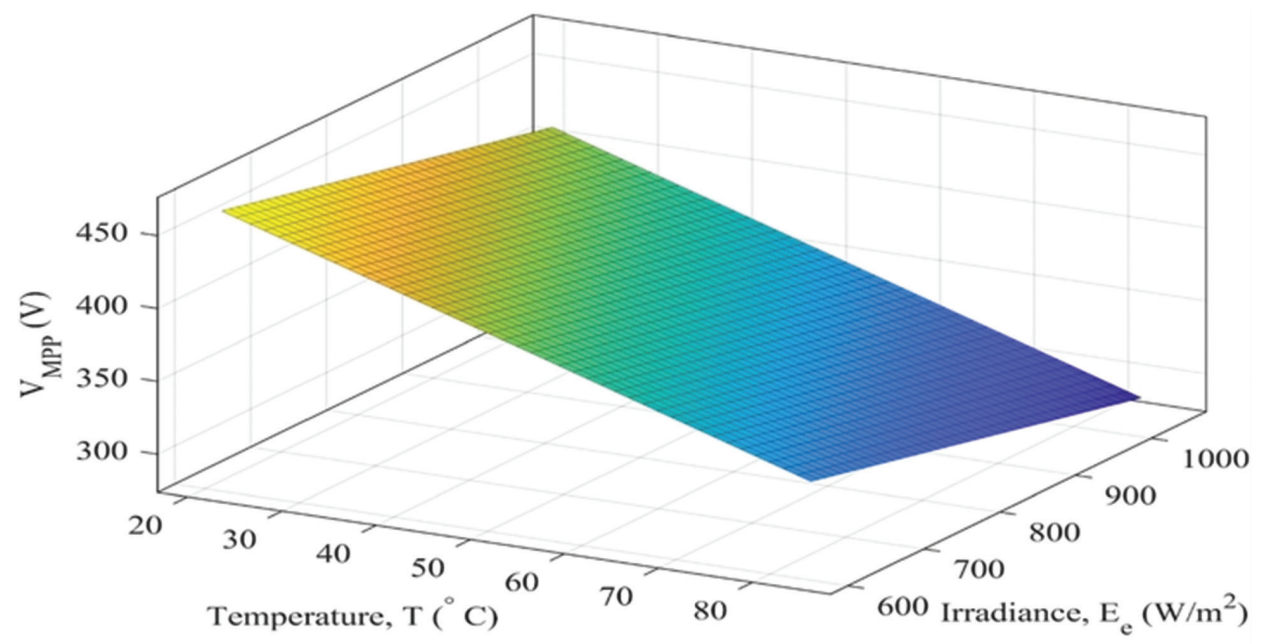

Fig. 3. MPPT reference voltage. 
In Eq. (24), $x_{2}$ acts as an effective controller input and $V_{1}$ as a positive Lyapunov candidate function, to check the merging of $e_{1}$ to zero.

$$
V_{1}=\frac{1}{2} e_{1}^{2}
$$

To prove asymptotic stability, the Lyapunov must be positive constant number and the derivative of Lyapunov w.r.t time should be negative constant.

Now, the derivative of Eq. (25) gives the following expression-

$$
\dot{V}_{1}=e_{1} \dot{e}_{1}
$$

Using the error derivative value from Eq. (24) in Eq. (26) we obtain:

$$
\dot{V}_{1}=e_{1}\left(\frac{I_{p v}}{C_{i}}-\mu \frac{x_{2}}{C_{i}}-\dot{V}_{r e f}\right)
$$

To bring the robust nature into the back-stepping algorithm, the equation for $\mathrm{x}_{2}$ is as follows

$$
x_{2 r e f}=\left(\frac{I_{p v}}{C_{i}}-\dot{V}_{r e f}+k_{1} e_{1}+k_{2} \operatorname{sign}\left(e_{1}\right)\right) \frac{C_{i}}{\mu}
$$

where $k_{1}$ and $k_{2}$ must be some positive value constants. With this option of $x_{2}$, Eq. (27) takes the following form:

$$
\dot{V}_{1}=-k_{1} e_{1}^{2}-k_{2} e_{1} \operatorname{sign}\left(e_{1}\right)
$$

Now, treating $\mathrm{x}_{\text {2ref }}$ as a new reference for further steps, it is tracked via second state of the PV system. This tracking error is as follows:

$$
e_{2}=x_{2}-x_{2 r e f}
$$

and

$$
x_{2}=e_{2}+x_{2 r e f}
$$

Putting Eq. (31) in Eq. (27), one may get:

$$
\dot{V}_{1}=e_{1}\left(\frac{I_{p v}}{C_{i}}-\mu\left(e_{2}+\frac{x_{2 r e f}}{C_{i}}-\dot{V}_{r e f}\right)\right.
$$

and

$$
\dot{V}_{1}=e_{1}\left(\frac{I_{p v}}{C_{i}}-\mu \frac{x_{2 r e f}}{C_{i}}-\dot{V}_{r e f}-\mu \frac{e_{2}}{C_{i}}\right)
$$


Substituting Eq. (29) in the above expression, one has:

$$
\dot{V}_{1}=-k_{1} e_{1}^{2}-k_{2} e_{1} \operatorname{sign}\left(e_{1}\right)-\mu \frac{e_{2} e_{1}}{C_{i}}
$$

The above inequality can be patronised as follows:

$$
\dot{V}_{1}=-2 k_{1} V_{1} \sqrt{2 k_{2}} \sqrt{V_{1}}-\mu \frac{e_{2} e_{1}}{C_{i}}
$$

Now, differentiating Eq. (31) with time, it gives-

$$
\dot{V}_{1}=\dot{x}_{2}-\dot{x}_{2 r e f}
$$

where the time derivative of $x_{2 \text { ref }}$ and $\dot{x}_{2 \text { ref }}$ are calculated as follows:

$$
\dot{x}_{2 \text { ref }}=\frac{1}{\mu^{2}}\left[(\mu)\left(\dot{I}_{p v}-C_{i} \dot{V}_{r e f}+k_{1} C_{i} \dot{e}_{1}\right)-\left(I_{p v}-C_{i} \dot{V}_{r e f}+k_{1} C_{i} e_{1}+k_{2} C_{i} \operatorname{sign}\left(e_{1}\right)\right)(\dot{\mu})\right]
$$

After some algebraic simplification, $x_{2 \text { ref }}$ becomes-

$$
\dot{x}_{2 r e f}=\frac{1}{\mu}\left[\dot{I}_{p v}-C_{i} \ddot{V}_{r e f}-C_{i} k_{1}^{2} e_{1}-C_{i} k_{1} k_{2} \operatorname{sign}\left(e_{1}\right)\right]-k_{1} e_{2}-\dot{\mu} \mu x_{2 r e f}
$$

Using it in Eq. (36), one has

$$
\dot{e}_{2}=\dot{x}_{2}-\left[\left(\frac{1}{\mu}\right)\left(\dot{I}_{p v}-C_{i} \dot{V}_{r e f}-C_{i} k_{1}^{2} e_{1}-C_{i} k_{1} k_{2} \operatorname{sign}\left(e_{1}\right)-k_{1} e_{2}-\dot{\mu} \mu x_{2 r e f}\right)\right.
$$

A combination of Lyapunov functions, $V_{c}$, by defining the convergence of errors to 0 , and the stability of the PV system, becomes

$$
V_{C}=V_{1}+\frac{e_{2}^{2}}{2}
$$

The time derivative of $\mathrm{V}_{\mathrm{c}}$, with Eq. (34), is taken into account, and it becomes:

$$
\dot{V}_{c}=-k_{1} e_{1}^{2}-k_{2} e_{1} \operatorname{sign}\left(e_{1}\right)+e_{2}\left(\dot{e}_{2}-\mu \frac{e_{1}}{C_{i}}\right)
$$

For $\mathrm{Vc}_{\mathrm{c}}$ to be negative definite, let

$$
\dot{e}_{2}-\mu \frac{e_{1}}{C_{i}}=-k_{3} e_{2}-k_{4} \operatorname{sign}\left(e_{2}\right)
$$


where $\mathrm{k}_{3}$ and $\mathrm{k}_{4}$ are positive gain constants. Utilising the values of $\dot{e}_{2}$ Eq. (42) and $\dot{x}_{2}$ from Eq. (7) in Eq. (41), we obtain

$$
\begin{aligned}
& -k_{3} e_{2}-k_{4} \operatorname{sign}\left(e_{2}\right)=-\mu \frac{e_{1}}{C_{i}}+\left(\left(\mu \frac{V_{p v}}{L}\right)+\left(\frac{(\mu-1)}{L} V C_{0}\right)_{+}\right. \\
& -\left(\frac{1}{\mu}\right)\left(\dot{I}_{p v}-C_{i} \dot{V}_{r e f}-C_{i} k_{1}^{2} e_{1}-C_{i} k_{1} k_{2} \operatorname{sign}\left(e_{1}\right)+k_{1} e_{2}+\dot{\mu} \mu x_{2 r e f}\right)
\end{aligned}
$$

Solving Eq. (43) for $\dot{\mu}$, the final control law of reduced basis RB approximation techniques is as follows:

$$
\begin{aligned}
& \dot{\mu}=\mu x_{2 \text { ref }}\left[-k_{3} e_{2}-k_{4} \operatorname{sign}\left(e_{2}\right)+\mu \frac{e_{1}}{C_{i}}+k_{1} e_{2}\right]-\mu x_{2 r e f}\left[\left(\mu \frac{V_{p v}}{L}\right)+\left(\frac{(\mu-1)}{L}\right) V C_{0}\right]+ \\
& +\mu x_{2 r e f}\left[\left(\frac{1}{\mu}\right)\left(\dot{I}_{p v}-C_{i} \dot{V}_{r e f}-C_{i} k_{1}^{2} e_{1}-C_{i} k_{1} k_{2} \operatorname{sign}\left(e_{1}\right)\right]\right.
\end{aligned}
$$

Now, $\dot{u}$ can be written in continuous and discontinuous forms:

$$
\dot{u}=\dot{\mu}_{c o n t}+\dot{\mu}_{\text {dis }}
$$

As

$$
\begin{aligned}
& s=e_{1}=x_{1}-x_{r e f} \\
& \dot{\mu}_{d i s}=-k_{3} \sqrt{\mid s} \mid \operatorname{sign}(s)
\end{aligned}
$$

we can substitute Eq. (47) in Eq. (45), and we obtain:

$$
\dot{u}=\dot{\mu}_{\text {cont }}-k_{3} \sqrt{\mid s} \mid \operatorname{sign}(s)
$$

Such control was applied to PV modules with parameters given in Table 1. For simulation tests, parameters given in Table 2 were used.

Table 1. Photovoltaic module parameters

\begin{tabular}{lll}
\hline S. No & Parameters & Values \\
\hline \hline 1 & Maximum power & $1,555.416 \mathrm{~W}$ \\
2 & Number of cells/panels & 72 \\
3 & Open circuit voltage & $165.8 \mathrm{~V}$ \\
4 & Short circuit voltage & $17.56 \mathrm{~V}$ \\
5 & $\mathrm{~V}_{\mathrm{mp}}$ & $102.6 \mathrm{~V}$ \\
6 & $\mathrm{I}_{\mathrm{mp}}$ & $15.16 \mathrm{~A}$ \\
\hline
\end{tabular}


Table 2. Simulation parameters and its values

\begin{tabular}{|c|c|c|}
\hline S. No & Parameters & Values \\
\hline 1 & Capacitor C & $48 \mathrm{mF}$ \\
\hline 2 & Inductor L & $20 \mathrm{mH}$ \\
\hline 3 & Constant $\mathrm{k}_{1}$ & 170 \\
\hline 4 & Constant $\mathrm{k}_{2}$ & 1,200 \\
\hline 5 & Constant $\mathrm{k}_{3}$ & 4 \\
\hline 6 & Constant $\mathrm{k}_{4}$ & 8 \\
\hline 7 & Constant $\mathrm{a}_{1}$ & 1,000 \\
\hline 8 & IGBT switching frequency $f_{s}$ & $5,000 \mathrm{~Hz}$ \\
\hline 9 & Shunt resistance & $179.949 \Omega$ \\
\hline 10 & Series resistance & $3.1652 \Omega$ \\
\hline
\end{tabular}
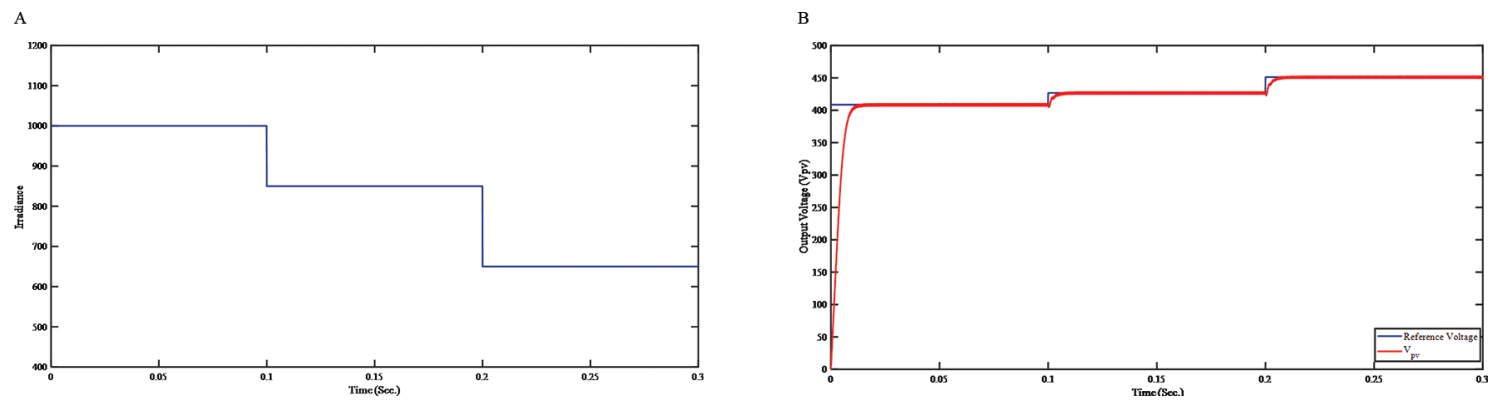

Fig. 4. Irradiance levels tested (a) and voltage $V_{p v}$ tracking performance of the proposed controller (b).

\section{Experimental Results}

The experimental results of the proposed controller are taken under various meteorological conditions. The results of the experiment show the merit and suitability of the proposed controller. The PV module is connected with the external load through NIBBC, which is controlled by BHOSMC. The details of the experimental outcomes are given in the following section.

The results under changing temperatures.

The results under changing irradiance.

The PV array consists of 16 panels which are connected in parallel and series and has 72 cells per panel.

\subsection{Testing under changing in irradiance}

Here, the temperature is kept constant at standard conditions and the irradiance is changed from $1,000 \mathrm{~W} / \mathrm{m}^{2}$ for $0.1 \mathrm{~s}$ to $850 \mathrm{~W} / \mathrm{m}^{2}$ for a duration from $0.1 \mathrm{~s}$ to $0.2 \mathrm{~s}$ and then to $650 \mathrm{~W} / \mathrm{m}^{2}$ for a duration from $0.2 \mathrm{~s}$ to $0.3 \mathrm{~s}$. The irradiance's levels changing with time is shown in Figure 4a. For changing irradiance levels, the reference voltage is generated by linear interpolation. The proposed controller quickly traced the reference voltage as shown in Figure 4b. The PV module output MPP is obtained with very less chattering or oscillation as shown in Figure 5. The MPP achieved by the proposed controller takes very less time under the fast variation of $0.1 \mathrm{~s}$.

\subsection{Testing under changing temperature}

Here, the tests were performed under constant irradiance of $1,000 \mathrm{~W} / \mathrm{m}^{2}$ and the temperature is changed from $25{ }^{\circ} \mathrm{C}$ for $0.1 \mathrm{~s}$ to $65^{\circ} \mathrm{C}$ for a duration from $0.1 \mathrm{~s}$ to $0.2 \mathrm{~s}$ and then to $25^{\circ} \mathrm{C}$ for a duration from $0.2 \mathrm{~s}$ to $0.3 \mathrm{~s}$. The temperature levels changing with time are shown in Figure 6 .

Once again the reference voltage is generated by linear interpolation for changing temperature levels. The proposed controller quickly traced the reference voltage as shown in Figure $6 \mathrm{~b}$. The PV module output MPP is 


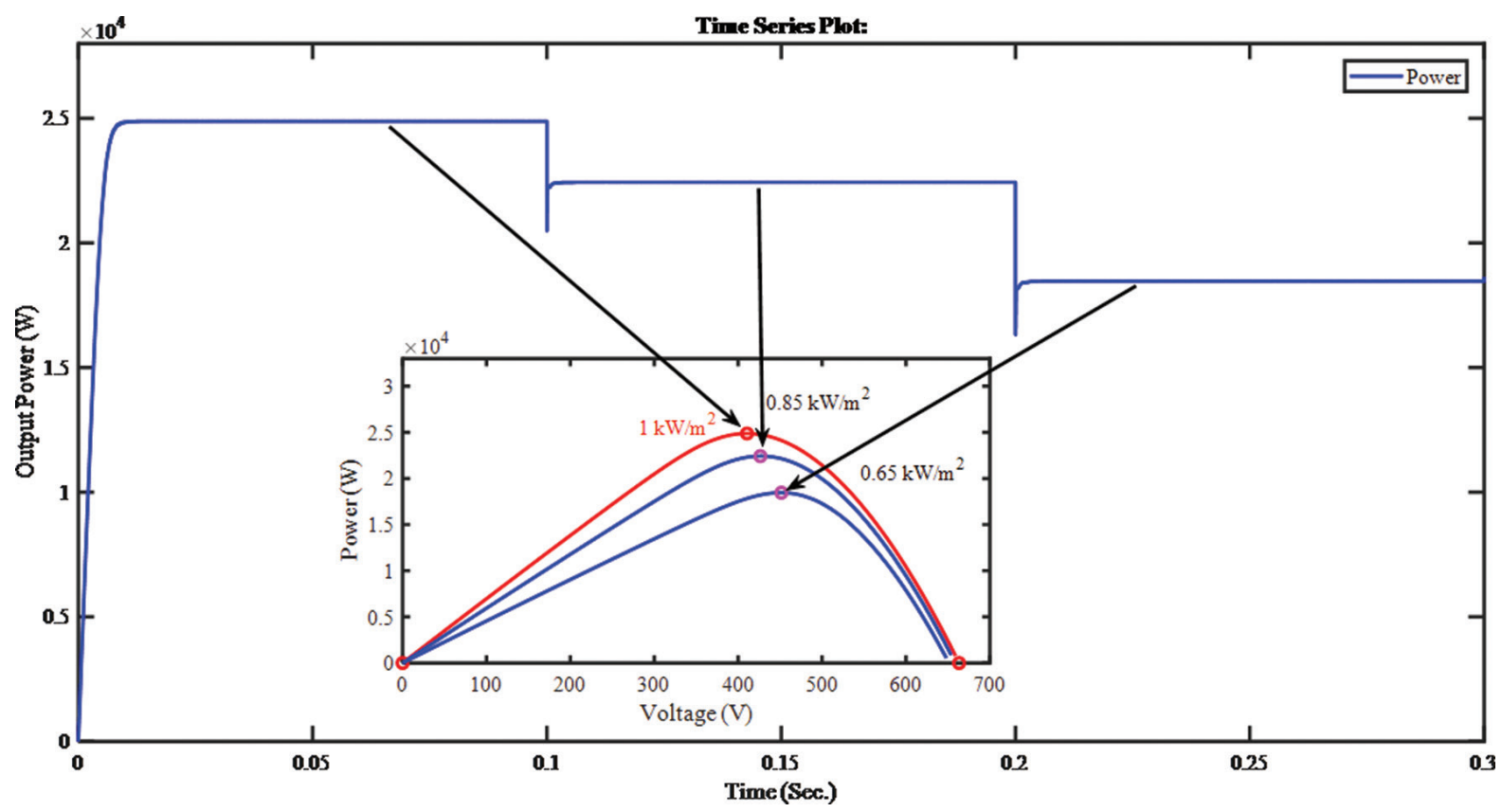

Fig. 5. PV output power with respect to changes in irradiance.
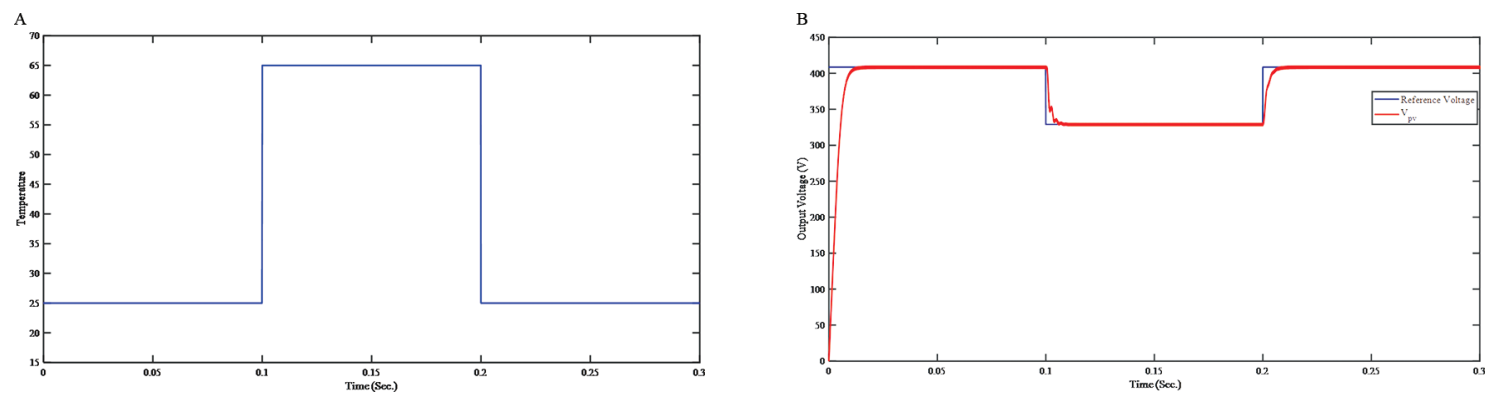

Fig. 6. Temperature levels tested (a) and voltage $V_{p v}$ tracking performance of the proposed controller (b).

obtained with very less chattering or oscillation as shown in Figure 7. The MPP achieved by the proposed controller takes very less time under fast variation in $0.1 \mathrm{~s}$.

\subsection{Comparison of the proposed controller with other MPPT controllers}

The performance of the BHOSMC is evaluated by comparing with other MPPT control techniques like P\&O, backstepping control (BSC) and back-stepping sliding mode control (BSMC), under varying irradiance and temperature. The irradiance changes from $1,000 \mathrm{~W} / \mathrm{m}^{2}$ for $0.1 \mathrm{~s}$ and then changes to $850 \mathrm{~W} / \mathrm{m}^{2}$ for a duration from $0.1 \mathrm{~s}$ to $0.2 \mathrm{~s}$; and then to $650 \mathrm{~W} / \mathrm{m}^{2}$ from $0.2 \mathrm{~s}$ to $0.3 \mathrm{~s}$. And similarly, the temperature changes from $25^{\circ} \mathrm{C}$ for $0.1 \mathrm{~s}$ and then changes to $40{ }^{\circ} \mathrm{C}$ for a duration from $0.1 \mathrm{~s}$ to $0.2 \mathrm{~s}$; and then to $60{ }^{\circ} \mathrm{C}$ for a duration from $0.2 \mathrm{~s}$ to $0.3 \mathrm{~s}$. We will do the comparison under two cases:

at normal conditions, and

at fault conditions.

\subsubsection{Normal conditions}

In the Figure 8, the comparison of the PV output voltage obtained using different control strategies at normal conditions is shown under varying temperature and irradiance. At normal condition, the controller performance 


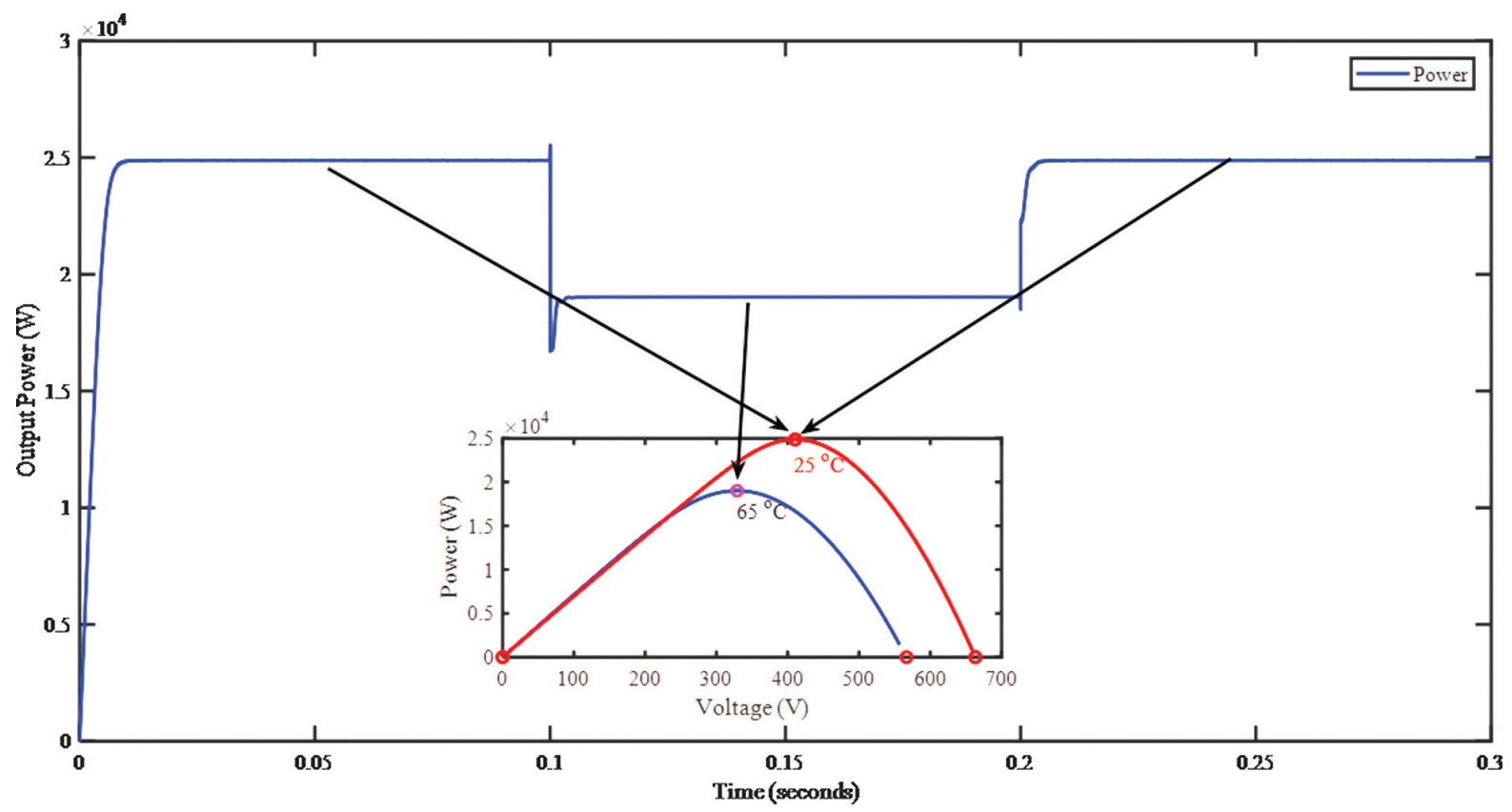

Fig. 7. PV output power with respect to changes in temperature.

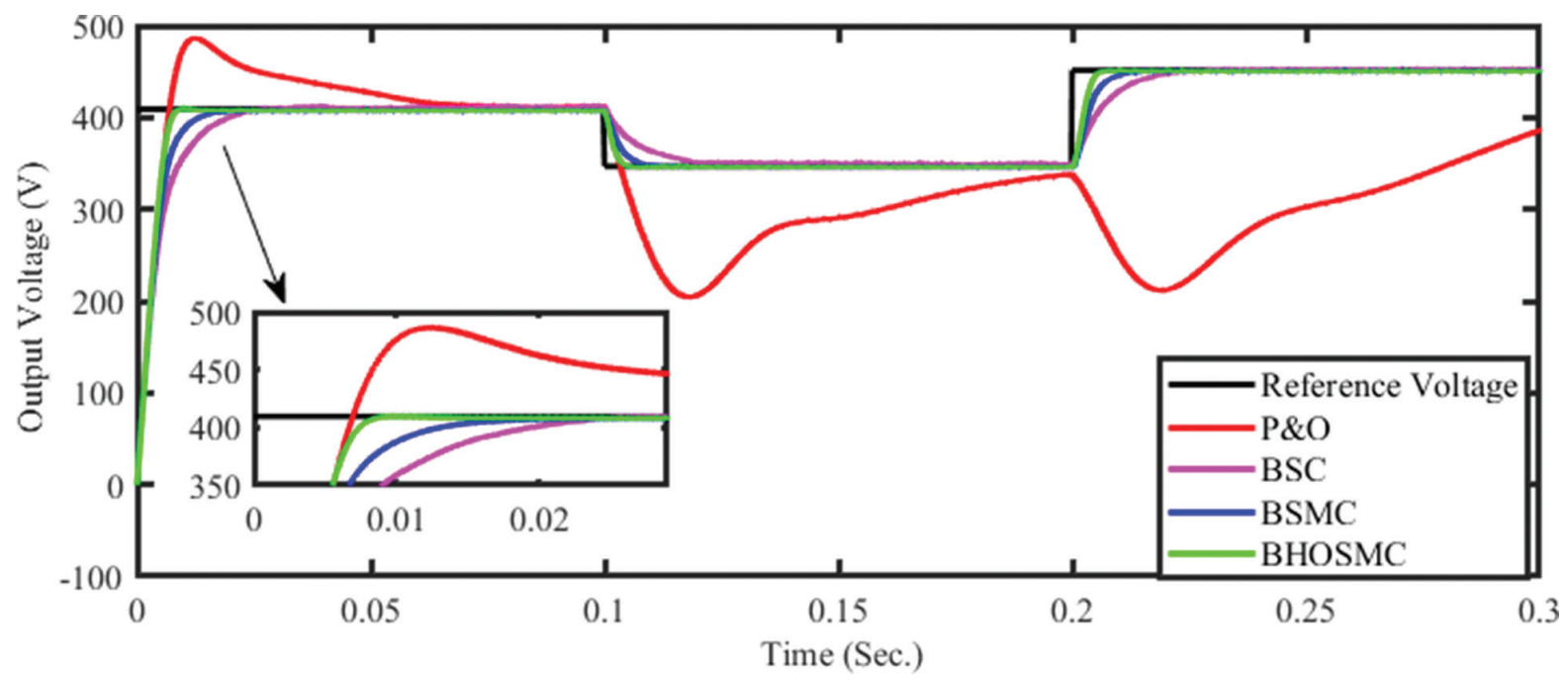

Fig. 8. The comparison of output voltage at normal condition using different controllers. BSC, back-stepping control; BSMC, back-stepping sliding mode control; BHOSMC, based higher order sliding mode controller; P\&O, perturb and observe.

indicates that P\&O method totally fails and the system response fully deviates from reference value. The red line shows P\&O controller response, the pink line shows BSC response, the blue line shows BSMC response and the green line shows the proposed BHOSMC response. Our proposed controller reaches the reference much quicker than $\mathrm{BSC}$ and $\mathrm{BSMC}$, shows fast convergence and much smaller error than BSC and BSMC.

In Figure 9, the comparison of output power of the PV system is presented at normal condition under varying temperature and irradiance for different controllers. There is a very high chartering, which occurs at P\&O method as shown in this figure by the red line (also in zoom view). It shows very large deviation from the optimal line. The BSC controller (the pink line) action results in more chattering than P\&O, and also results in smaller deviation, slow convergence or bigger rising time than BSMC and BHOSMC. 


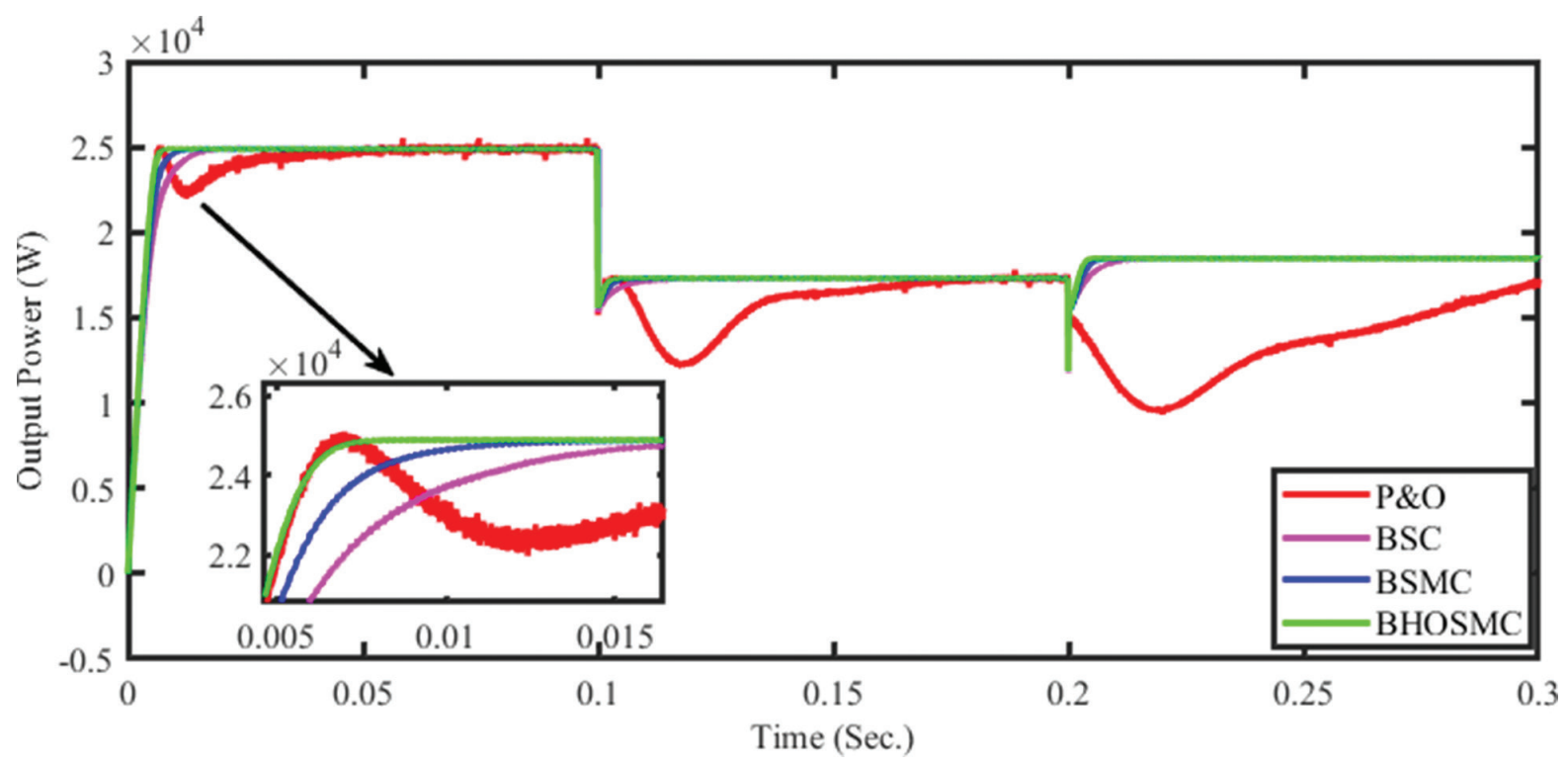

Fig. 9. The comparison of output power at normal condition using different controllers. BSC, back-stepping control; BSMC, back-stepping sliding mode control; BHOSMC, based higher order sliding mode controller; P\&O, perturb and observe.

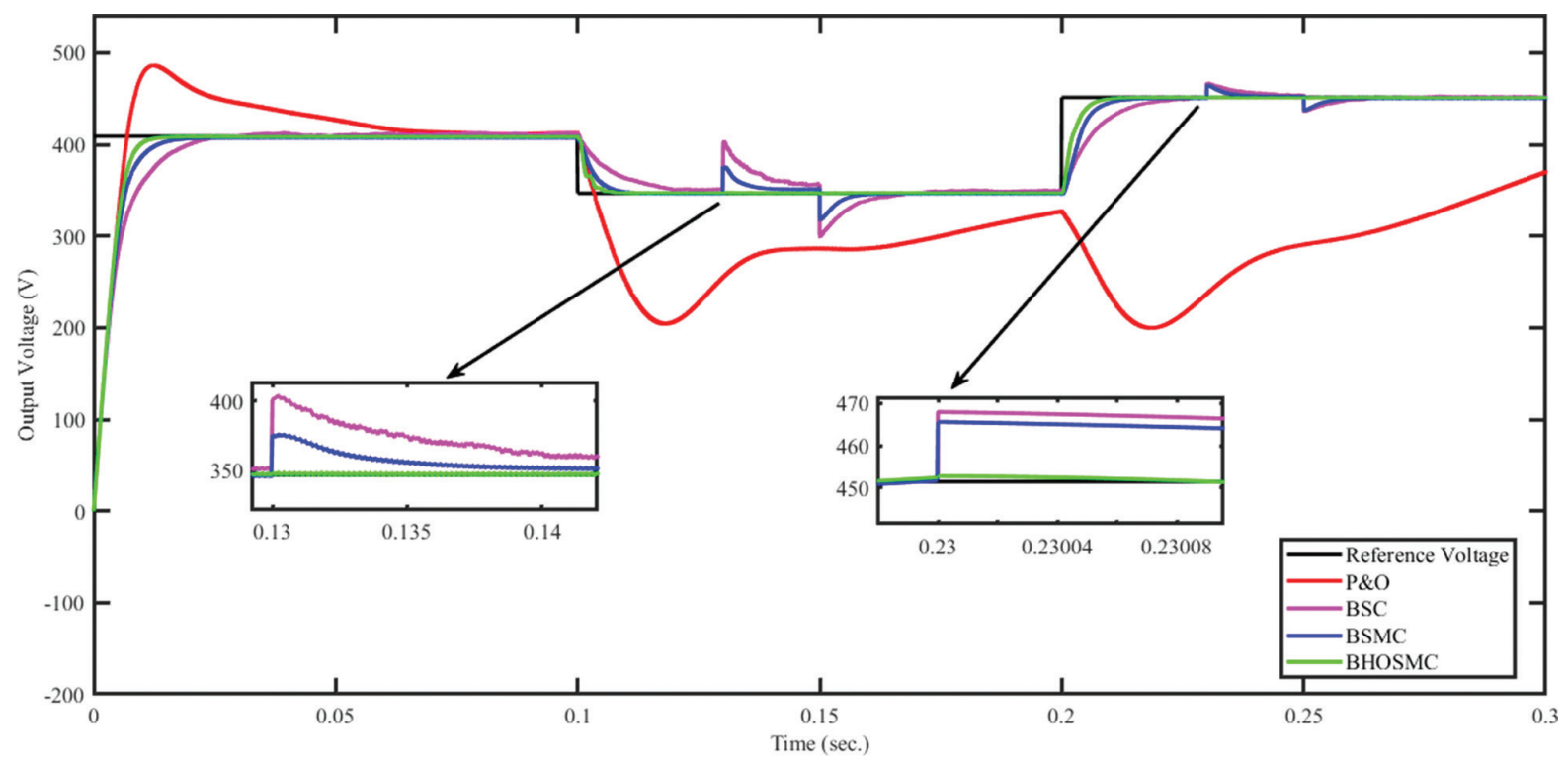

Fig. 10. Shows the output voltage's comparison graph under fault conditions. BSC, back-stepping control; BSMC, back-stepping sliding mode control; BHOSMC, based higher order sliding mode controller; P\&O, perturb and observe.

\subsubsection{Fault condition}

Similarly, we have done the comparison and analysed four controllers by checking the performance under varying temperature and irradiance under fault conditions (occurring at $t=0.13 \mathrm{~s}$ and $t=0.15 \mathrm{~s}$ ). Figure 10 shows the output voltage's comparison graphs under these conditions. It clearly shows that the $\mathrm{P} \& \mathrm{O}$, which is shown by the red line, totally fails and largely deviates from the reference level. Also for BSC (pink line) and BSMC (blue line), the reaction to the fault is visible and some de-tracking from reference can be seen. On contrary, the proposed BHOSMC (green line) is robust to the disturbance and it is characterised by high convergence and less chattering; and additionally, it is faultless.

In Figure 11, the comparison of output power at fault condition is shown. P\&O controller totally fails as shown by the red line in this figure. It shows very large deviation from a normal line. In the case of BCS (pink line), we can 


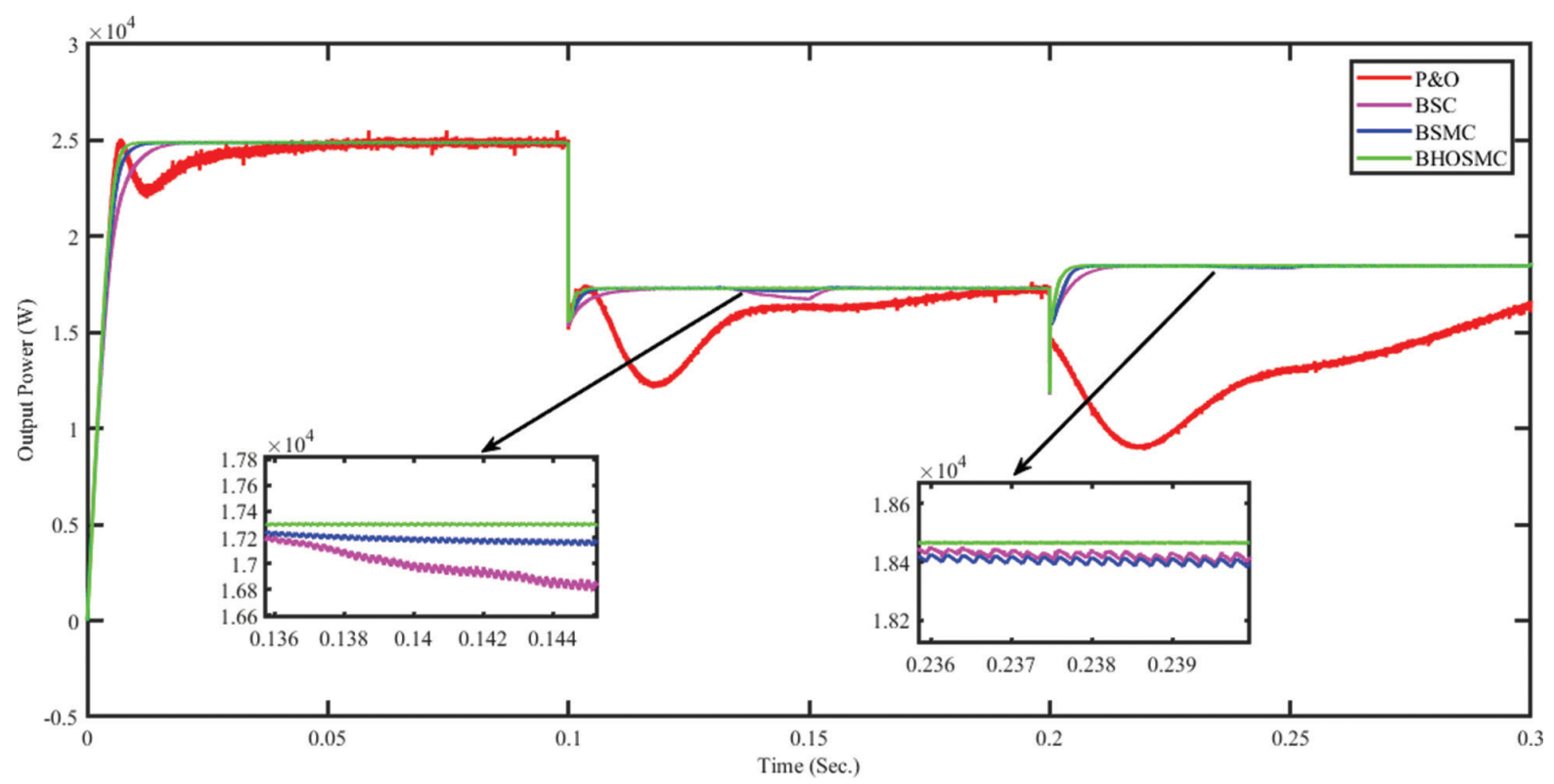

Fig. 11. The comparison of the output power at fault condition using different controllers. BSC, back-stepping control; BSMC, back-stepping sliding mode control; BHOSMC, based higher order sliding mode controller; $\mathrm{P} \& \mathrm{O}$, perturb and observe.

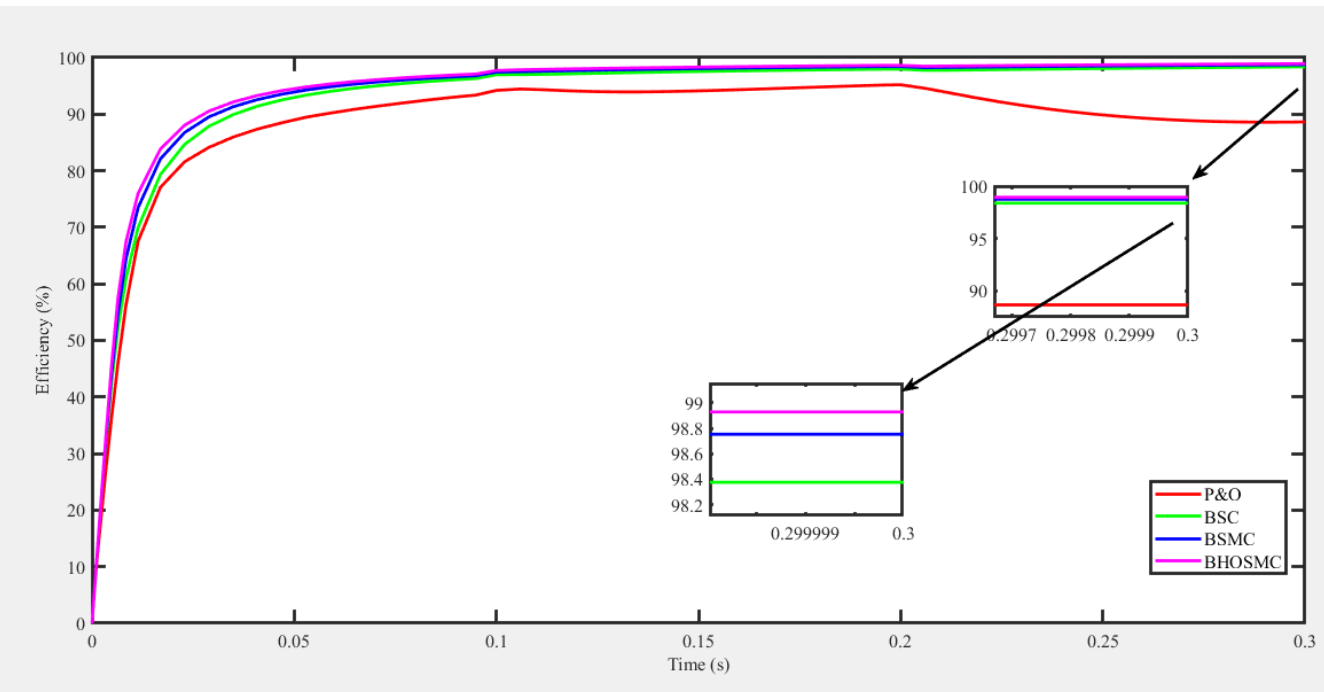

Fig. 12. Efficiency comparison for the PV system with different controllers. BSC, back-stepping control; BSMC, back-stepping sliding mode control; BHOSMC, based higher order sliding mode controller; P\&O, perturb and observe.

observe more chattering than for $\mathrm{P} \& \mathrm{O}$, but smaller deviation, much slower convergence and bigger rising time than BSMC and BHOSMC. BSMC is good in the case of fault condition, but it is indicative of the chattering problem, which we see the zoom view.

\subsubsection{Efficiency of the proposed controller}

In the Figure 12, the result of efficiency calculations for the systems with the analysed controllers are presented.

\section{Conclusion}

In this study, for harvesting MPP from PV system, a non-linear back-stepping BHOSMC is designed. To track MPP, the NIBBC duty cycle is controlled and the load of the PV panels is connected through NIBBC. The reference 
voltage of regression plane is generated by linear interpolation, which then traces for MPP using the proposed controller. The experimental result demonstrates the significance of the proposed BHOSMC in a fast changing meteorological condition. The proposed controller is robust and efficient, has less chattering and also is faultless as compared to other well designed MPPT techniques like P\&O, BSC and BSMC.

\section{Acknowledgement}

The research work is a self-study and is not funded by any organisation or body.

\section{References}

Armghan, H., Ahmad, I., Armghan, A., Khan, S. and Arsalan, M. (2018). Backstepping Based Nonlinear Control for Maximum Power Point Tracking in Photovoltaic System. Solar Energy, 159, pp. 134-141.

Başoğlu, M. E. and Çakır, B. (2016). Comparisons of MPPT Performances of Isolated and Non-isolated DC-DC Converters by Using a New Approach. Renewable and Sustainable Energy Reviews, 60, pp. 1100-1113.

Bellia, H., Youcef, R. and Fatima, M. (2014). A Detailed Modeling of Photovoltaic Module Using MATLAB. NRIAG Journal of Astronomy and Geophysics, 3(1), pp. 53-61.

Dincer, F. (2011). The Analysis on Photovoltaic Electricity Generation Status, Potential and Policies of the Leading Countries in Solar Energy. Renewable and Sustainable Energy Reviews, 15(1), pp. 713-720.

El Fadil, H. and Giri, F. (2007). Backstepping Based Control of PWM DC-DC Boost Power Converters. IEEE International Symposium on Industrial Electronics, pp. 395-400.

Elgendy, M. A., Zahawi, B. and Atkinson, D. J. (2012). Assessment of the Incremental Conductance Maximum Power Point Tracking Algorithm. IEEE Transactions on Sustainable Energy, 4(1), pp. 108-117.

Elgendy, M. A., Zahawi, B. and Atkinson, D. J. (2012). Evaluation of Perturb and Observe MPPTAlgorithm Implementation Techniques. IET International Conference on Power Electronics, Machines and Drives, pp/ 110-110.

Elobaid, L. M., Abdelsalam, A. K. and Zakzouk, E. E. (2015). Artificial Neural Network-based Photovoltaic Maximum Power Point Tracking Techniques: A Survey. IET Renewable Power Generation, 9(8), pp. 1043-1063.

Gohar Ali, H, Arbos, R. V., Herrera, J., Tobón, A. and Peláez-Restrepo, J. (2020). Non-Linear Sliding
Mode Controller for Photovoltaic Panels with Maximum Power Point Tracking. Processes, 8(1), pp. 108.

Gohar Ali, H. and Arbos, R. V. (2020). Chattering Free Adaptive Sliding Mode Controller for Photovoltaic Panels with Maximum Power Point Tracking. Energies, 13(21), pp. 5678.

Hua, C. and Shen, C. (1998). Comparative Study of Peak Power Tracking Techniques for Solar Storage System. Applied Power Electronics Conference and Exposition, 1998. APEC'98. Conference Proceedings 1998., Thirteenth Annual. 2, pp. 679685.

Iftikhar, R., Ahmad, I., Arsalan, M., Naz, N., Ali, N. and Armghan, H. (2018). MPPT for Photovoltaic System Using Nonlinear Controller. International Journal of Photoenergy, 2018.

Metry, M., Shadmand, M. B., Balog, R. S. and AbuRub, H. (2016). MPPT of Photovoltaic Systems Using Sensor Less Current-based Model Predictive Control. IEEE Transactions on Industry Applications, 53(2), pp. 1157-1167.

Sera, D., Mathe, L., Kerekes, T., Spataru, S. V. and Teodorescu, R. (2013). On the Perturb-andObserve and Incremental Conductance MPPT Methods for PV Systems. IEEE Journal of Photovoltaics, 3(3), pp. 1070-1078.

Smith, J. L. (2009). World Oil: Market or Mayhem?. Journal of Economic Perspectives, 23(3), pp. 145-164.

Villalva, M. G., Gazoli, J. R. and Filho, E. R. (2009). Comprehensive Approach to Modeling and Simulation of Photovoltaic Arrays. IEEE Transactions on Power Electronics, 24(5), pp. 1198-1208, doi: 10.1109/TPEL.2009.2013862.

Zhang, H. L., Baeyens, J., Degrève, J. and Cacères, G. (2013). Concentrated Solar Power Plants: Review and Design Methodology. Renewable and Sustainable Energy Reviews, 22, pp. 466-481. 